\title{
Object-Oriented Context Description for Movie Based Context-Aware Language Learning
}

\author{
Hazriani* $^{* \dagger}$, Tsuneo Nakanishi ${ }^{\ddagger}$, Kenji Hisazumi $^{\S}$, and Akira Fukuda \\ *Department of Computer System, School of Management Informatics and Computer (STMIK) Handayani \\ Makassar 90231, Indonesia \\ ${ }^{\dagger}$ School of Information Science and Electrical Engineering, Kyushu University \\ Fukuoka 819-0395, Japan \\ ${ }_{\ddagger}$ Department of Electronic Engineering and Computer Science, Faculty of Engineering, Fukuoka University \\ Fukuoka 814-0180, Japan \\ $\S$ System LSI Research Center, Kyushu University, \\ Fukuoka 819-0395, Japan \\ ॠFaculty of Information Science and Electrical Engineering, Kyushu University \\ Fukuoka 819-0395, Japan
}

\begin{abstract}
Context-aware ubiquitous learning is a promising way to learn languages; however, it requires developers and operators of much effort to construct, deploy, and use the specialized system. As its alternative, this paper proposes movie based context-aware language learning (MBCALL) that enables learners to learn languages through quizzes generated along virtual contexts occurring in the movie to be replayed. Since full automatic context capturing from the movie is impossible, the authors define an object-oriented context model (OOCM) and also a textual context description language subject to the OOCM to describe the movie context easily by human work. The OOCM introduces the case grammar concept of natural language processing. This enables quiz generation based on types of the words for objects, actions, and modes found in the movie. Evaluation with a small movie by three subjects shows that the OOCM can guide them to enrich information included in the movie context; therefore, we can generate more types of quizzes based on the movie context.
\end{abstract}

Keywords-Movie based context-aware language learning (MBCALL); object-oriented context model (OOCM); context description language; case grammar

\section{INTRODUCTION}

So far many context-aware ubiquitous learning systems have shown that learning from real environment is attractive and effective for learners. However, it requires developers and operators to make much effort for using context-aware ubiquitous learning systems in practice. Developers have to develop complicated learning applications interacting with real environment through various sensors and smart devices. Operators have to prepare contextual learning materials that can provide learning tasks reacting to dynamic situations. Physical devices deployed in real environment can be out of order by long time operation under harsh environment such as outdoors. Availability of real time network connection is another important issue to be concerned. These matters will lead more development and operation cost or limited functionality of the learning system.

The movie can be a place in where context-aware ubiquitous learning is virtually practiced. The authors propose the concept of movie based context-aware learning (or MBCAL for short) as an alternative approach for context-aware ubiquitous learning to overcome the above-mentioned difficulties on development and operation [1]. MBCAL utilizes movies to facilitate learner's proactive learning from the context situated in the scenes as ubiquitous learning systems try to do in real environment. Moreover, it does not require any physical equipment to be deployed in real environment and any specific learning applications interacting with them, since every learning is performed in the movie player with learning functions. Considering the movie has been utilized to teach languages so far, one of the most suitable MBCAL applications will be language learning, which is hereinafter called as Movie Based Context-Aware Language Learning (or MBCALL for short). This paper focuses solely on MBCALL.

In MBCALL, the learner watches the movie and the movie player with learning functions generates quizzes automatically based on both movie's and learner's contexts [2]. The MBCALL system generates different quizzes to different learners depending on their different contexts even for the same movie.

The movie context is the current scene of the replayed movie and any information derived from it. It is desirable to compose the movie context description automatically from the movie; however, considering state-of-the-art image and phonetic recognition and understanding technologies, only a limited class of automatic composition is possible. Moreover, the movie sometimes includes the context which is not represented explicitly and is deduced from its story or implication. Therefore, human work is needed for composition of the movie context. The instructor describes the movie context by language independent context description and associates them with relating movie frames. This paper defines and evaluates a language for movie context description.

On the other hand, the learner context is information relating to the learner such as his/her learning level, completed learning tasks, watched/unwatched movies, and preferred movies. It is initially given by the learner him/herself and updated by the system along with his/her learning activity.

Followed by related work in Section II, the authors show 
the standing point of the movie based context-aware learning as well as its comprehensive comparison to existing learning paradigms in Section III. Section IV presents a scheme to describe the movie context with the object-oriented context model (or OOCM for short) and the textual context description based on the model, which are key conceptual contribution of this paper. In Section V, the authors evaluate how the OOCM can guide us to enrich information included in the movie context. Finally, Section VI concludes the paper.

\section{RELATED WORK}

Development of information and communication technology (ICT) has derived a series of emerging learning paradigms. Ogata and Uosaki presented a research map on use of computers in education that identifies six emerging learning paradigms including CAI (computer assisted instruction) / ITS (intelligent tutoring system), game based learning (GBL), computer supported collaboration learning (CSCL), web based learning (or e-learning), mobile learning (or m-learning), and ubiquitous learning (or u-learning), along with involved ICTs and their contribution to user behaviors [3].

CAI is a form of computer supported learning and teaching using fixed PC, which was introduced in 1960s. Later, researchers incorporated artificial intelligence into CAI to improve learning and problem solving [4], which is known as ITS or ICAI (Intelligent CAI).

GBL, which was introduced in 1980s along with emergence of multimedia technologies, is another type of learning incorporating the subject matter into game play with defined learning outcomes. The learner can apply what they have learned to the real world through the game play.

CSCL, which is derived by invention of the world wide web (WWW) in 1990, facilitates interaction and collaboration among a group of learners connected each other.

E-learning facilitates learning on web based services in the internet.

M-learning facilitates learning in mobility, which is realized by mobile and wireless network and technologies.

U-learning facilitates learning through learner's surroundings captured by mobile, wireless, and ubiquitous network and technologies such as sensors and RFIDs.

E-, m-, and u-learnings have similar potential in enhancing social interaction and cooperative learning among learners through network. Moreover, u-learning enables learning from experience through interaction between cyber and physical spaces. Various research and commercial applications of these learning paradigms are available in various learning domains.

Movie based learning is an alternative way to achieve learning from experience, although the experience is virtual. Therefore, the movie has been practically used for learning so far. Kerber et al. encouraged students to learn the medical theory from corresponding provided movies [5]. Lumlertgul et al. conducted a cinemeducation project, which aimed to help students learn medical professionalism using movies [6]. Jungraithmayr and Weder improved the learning process on technique of orthotropic mouse lung transplantation with fulllength movie visualization [7].
Furthermore, the movie can facilitate to learn context dependent aspects of the language. Chan and Herrero used movie clips to teach various languages in the classroom in their project and stated that plentiful contexts in the movie can be utilized for language learning as same as real environment, as it is known that the movie can facilitate comprehension activities perceived as real [8]. Ismaili showed effectiveness of using movies in the EFL classroom [9].

It is demonstrated by these researchers that movies improve student's understanding significantly and attract student's attention successfully. Additionally, in the field of language learning, the movie presents languages naturally as well as shows quite rich linguistic and environmental contexts that can be perceived as real. Considering the above-mentioned facts, the authors are motivated to incorporate the movie into a learning platform and develop an MBCALL system.

\section{Movie BAsed CONTEXT-AwARE LEARning}

Movie based context-aware learning, which the authors propose, is a concept that introduces context-awareness into movie based learning. MBCAL enables learning from virtual experience in the movie as efficiently as u-learning that enables learning from experience in real environment through ubiquitous networks and technologies.

To compare MBCAL with e-, m-, and u-learnings and clarify differences, the authors surveyed existing work in the field of e-, m-, and u-learnings and adopt six features for comparison including permanency, accessibility, immediacy, interactivity, context-awareness, and content of the learning portfolio. The features except the content of the learning portfolio are adopted by many researchers as presented in [10], [11], [12] and [13]. The content of the learning portfolio is solely mentioned in [11]. These features are too abstract to differentiate the learning paradigms; thus, the authors define some levels of functionality with explanation for each feature.

As shown in Table I, these four learning paradigms can be accessed through the wireless network, show contextawareness based on the learning portfolio, and record learner's online behavior. Both e-learning and MBCAL can be accessed also via the wired network, while m-learning and u-learning must be accessed via the wireless network for its inherent characteristics. Both u-learning and MBCAL are able to keep learner's work permanently and provide dynamic adaptive services. In terms of interactivity, u-learning shows effective interactivity with peers, teachers, and experts. While both $\mathrm{m}-$ learning and MBCAL may have active interactivity, e-learning has interactivity in a limited form. Furthermore, the most recognized advantage of u-learning is context-awareness by both learner's physical context and real environment context. On the other hand, MBCAL shows context-awareness by utilizing virtual environment; i.e. movie scenes but with some technical limitations in performing real/physical context in $\mathrm{u}-$ learning. Lastly, u-learning records all aspects as the learning portfolio; namely, on-line behaviors, real-world behaviors, and corresponding environmental information of the learner. The others record online behaviors only.

In short, MBCAL has closest functionality to u-learning. Although it has functionality almost common to u-learning, 
TABLE I. COMPARISON OF LEARNING PARADIGMS

\begin{tabular}{|c|c|c|c|c|c|}
\hline Features & $\begin{array}{l}\text { Functionality } \\
\end{array}$ & e-learning & m-learning & u-learning & MBCAL \\
\hline \multirow[t]{3}{*}{ Permanency } & The leaner cannot keep learning record. & $\mathrm{X}$ & & & \\
\hline & The learner can keep learning record partially. & & $\mathrm{X}$ & & \\
\hline & The learner can keep every learning record. & & & $\mathrm{X}$ & $\mathrm{X}$ \\
\hline \multirow[t]{3}{*}{ Accessibility } & $\begin{array}{l}\text { The learner can access the system via the com- } \\
\text { puter network. }\end{array}$ & $\mathrm{X}$ & & & $\mathrm{X}$ \\
\hline & $\begin{array}{l}\text { The learner can access the system via the wireless } \\
\text { network. }\end{array}$ & $\mathrm{X}$ & $\mathrm{X}$ & $\mathrm{X}$ & $\mathrm{X}$ \\
\hline & $\begin{array}{l}\text { The learner and related devices can communicate } \\
\text { with ubiquitous technologies. }\end{array}$ & & & $\mathrm{X}$ & \\
\hline \multirow{2}{*}{ Adaptive Services } & $\begin{array}{l}\text { The learner can get information immediately in } \\
\text { fixed environment. }\end{array}$ & & $\mathrm{X}$ & & $\mathrm{X}$ \\
\hline & $\begin{array}{l}\text { The learner can get information immediately in } \\
\text { dynamic environment (as active services). }\end{array}$ & & & $\mathrm{X}$ & \\
\hline \multirow[t]{3}{*}{ Interactivity } & $\begin{array}{l}\text { The learner can interact with peers, teachers, and } \\
\text { experts in a limited form. }\end{array}$ & $\mathrm{X}$ & & & \\
\hline & $\begin{array}{l}\text { The leaner can interact with peers, teachers, and } \\
\text { experts actively. }\end{array}$ & & $\mathrm{X}$ & & $\bar{X}$ \\
\hline & $\begin{array}{l}\text { The learner can interact with peers, teachers, and } \\
\text { experts effectively. }\end{array}$ & & & $\mathrm{X}$ & \\
\hline \multirow[t]{4}{*}{ Context-Awareness } & $\begin{array}{l}\text { The system can provide context-aware learning } \\
\text { based on the learning portfolio. }\end{array}$ & $\mathrm{X}$ & $\mathrm{X}$ & $\mathrm{X}$ & $\mathrm{X}$ \\
\hline & $\begin{array}{l}\text { The system can provide context-aware learning } \\
\text { based on learner's personal context (physical con- } \\
\text { text). }\end{array}$ & & & $\mathrm{X}$ & \\
\hline & $\begin{array}{l}\text { The system can provide context-aware learning } \\
\text { based on the context of real environment. }\end{array}$ & & & $\mathrm{X}$ & \\
\hline & $\begin{array}{l}\text { The system can provide context-aware learning } \\
\text { based on the context of virtual environment. }\end{array}$ & & & & $\mathrm{X}$ \\
\hline \multirow{3}{*}{$\begin{array}{l}\text { Content of Learning } \\
\text { Portfolio }\end{array}$} & The system records the online behaviors. & $\mathrm{X}$ & $\mathrm{X}$ & $\mathrm{X}$ & $\mathrm{X}$ \\
\hline & The system records the real-world behaviors. & & & $\mathrm{X}$ & \\
\hline & $\begin{array}{l}\text { The system records the corresponding environ- } \\
\text { mental information of the learner. }\end{array}$ & & & $\mathrm{X}$ & \\
\hline
\end{tabular}

MBCAL has one unique functionality; that is, contextawareness in virtual environment. Note that Table I lists possible aspects of functionality that each learning paradigm may show generally; yet, in practice, an application of each learning paradigm may not show all of them. Applications of a certain learning paradigm may show slightly different functionality depending on their purposes.

\section{Object-Oriented Context Model and Textual CONTEXT DESCRIPTION}

In the MBCALL system, learners learn vocabularies and language expressions along the context in the movie. In contrast to the context-aware u-learning system which requires sensing devices and other data sources to acquire the context of physical environment, MBCALL requires none of them. Instead, MBCALL requires context description of movie scenes to be prepared before learning. Quizzes and their expected answers are generated based on the context description prepared for the movie.

The context description must be uniform, universal, and natural language independent to guarantee its reusability for different languages [14]. The authors have introduced the object-oriented paradigm and defined an object-oriented context model (or OOCM for short) to achieve this goal. The OOCM introduces the case grammar concept, which is a concept in the field of natural language processing, for its definition. The textual description based on the OOCM is defined as a means to describe the movie scenes.

\section{A. Case Grammars}

Fillmore proposed the case grammar concept [15]. The basic structure of the sentence can be divided into a couple of constituents: proposition and modality. The proposition consists of a tenseless set of relationships involving verbs and cases. The verb represents an event or activity, while cases are nouns having semantical relationships to the verb. Fillmore defines the following cases:

- Agentive: Who causes the event or activity?

- Instrument: What is used for the event or activity?

- Dative: Who experienced the event or activity?

- Factitive: What is the result of the event or activity?

- Locative: Where the event or activity happens?

- Objective: What is the target of the event or activity?

The modality includes such modalities on the sentence asa-whole as negation, tense, mood, and aspect. For example, "Alice slices the bread with the knife" can be broken into Alice as agentive, cut as verb, bread as objective, and knife as instrument.

Followed by Fillmore, many linguists have refined his case grammar concept and introduced more cases. The authors surveyed those works[15], [16], [17], [18] and summarized as shown in Table II. Note that there are some cases which have the same or similar meaning but are named differently by different linguists; for example, Fillmore's agentive is renamed as agent by Jurafsky and Martin[16] and as cAgent by Parunak[17].

The cases in the table have the following meanings:

- An agent means a perceived instigator of the action of the verb. 
- An object means a thing affected by the action or state of the verb.

- An instrument means force or an inanimate object casually involved in the state or action of the verb.

- An experiencer means an entity whose mental or emotional state is affected by the action of the verb.

- A factitive means a thing produced by the action of the verb.

- A goal means a place to where something moves or thing toward which an action is directed.

- A beneficiary means an entity that possesses an object or participates with an agent in transfer of an object.

- A manner means how the action, experiences, or process of an event is carried out.

- A time indexes the action of the verb in time.

- A location identifies the place or spatial orientation of the state or action.

- A measure means quantification of the event.

- A source means the place of the origin, entity from which a physical sensation emanates, or original owner in a transfer.

- A commutative refers to somebody else who performs an action with the agent.

- A complement means the new state of a factitive case.

- A causer means the referent which instigates an event rather than doing it actually.

\section{B. Object-Oriented Context Model based on the Case Gram- mar Concept}

Since the cases represent what the human being can cognize and verbalize, the case grammar concept can be used to describe movie scenes in a semantically formalized manner. The authors defined the OOCM integrating the case grammar concept for this purpose [14]. In this paper the OOCM of the previous work is improved for more comprehensive context description after writing movie contexts. The classes are defined by selecting cases from the summary shown in Section IV-A and mapping them on the OOCM as roles of the class. Fig. 1 shows the OOCM in the class diagram.

The OOCM has 11 classes. Classes Thing, Action, and Mode are the most fundamental ones.

- Class Thing means a thing appearing in the movie.

- Class Action means an action performed in the movie.

- Class Mode means a mode of the thing or the action.

Thing has the following descendant classes:

- Class Animate, a sub class of Thing, has its own intention.

- Class Inanimate, a sub class of Thing, does not have any intention.
- Class Object, a sub class of Inanimate, is something passively involved in the action.

- Class Space, a sub class of Inanimate, represents a location.

- Class Time, a sub class of Inanimate, represents a time instant of a duration.

Action has the following sub-classes:

- Class Transitive Action is an action that finishes immediately.

- Class Continuous Action is an action that continues for a certain duration.

\section{Context Description Language}

The movie context can be represented by the object diagram instantiated from the OOCM explained in the previous subsection. Since it is time consuming to edit the object diagram, the authors define the context description language (or CDL for short) to compose the movie context easily and quickly in a textual form. Fig. 2 shows the syntax of the CDL in the extended BNF in accordance with the current version of the OOCM.

The start symbol of the grammar is Contextscript. Symbol ClassName is the name of a class defined in the OOCM. Symbol AssocName is the name of an association between classes defined in the OOCM. ClassName and AssocName must be prefixed by the backslash ( $\backslash$ ). Symbol LanguageCode is a language code specified by ISO 6391[19] and 639-3[20] such as en for English, fr for French, $\mathrm{zh}$ for Chinese, etc. Symbol DQ represents a double quotation mark (").

For example, the movie scene shown in Fig. 3 can be modeled by the OOCM as shown in Fig. 4 and described in CDL as shown in Fig. 5.

\section{Evaluation}

In order to evaluate the descriptive power of the OOCM, the authors conducted an experiment by asking three volunteer subjects to describe the context of a public domain movie from Popeye the Sailor Series which is entitled as Insect to Injury [21]. The length of the movie clip is 6 minutes 7 seconds. The authors asked the subjects to describe the movie scenes in the free text without any more direction. Then the authors gave a short lecture on the OOCM and asked them to do the same thing again but with referencing the OOCM. All the subjects are Indonesian and they describe the movie scenes either in English or in Bahasa Indonesia, which is the common language in Republic of Indonesia.

Descriptions by the subjects were transformed into the OOCM for comparison. Movie contexts included in a single sentence can vary significantly depending on forms on writing. A complex sentence with more modifiers can have more meaning than a simple sentence. It enables fair comparison in a normalized form to transform a sentence into the OOCM and compare them based on the associations included in the OOCM. In comparison, the authors checked if the same type of association exists in the OOCMs describing the same movie 
TABLE II. Survey on the CASE Grammar [14]

\begin{tabular}{|c|c|c|c|c|c|c|}
\hline Cases & Fil. [15] & Long. [18] & Lar. [18] & Par. [17] & Berk. [18] & Jur. [16] \\
\hline Agentive (A) / Agent & $\mathrm{X}$ & $\mathrm{X}$ & $\mathrm{X}$ & $\mathrm{X}$ & $\mathrm{X}$ & $\mathrm{X}$ \\
\hline Instrumental (I) / Instrument & $\mathrm{X}$ & $\mathrm{X}$ & $\mathrm{X}$ & $\mathrm{X}$ & $\mathrm{X}$ & $\mathrm{X}$ \\
\hline Dative (D) / Experiencer (E) & $\mathrm{X}$ & $\mathrm{X}$ & - & $\mathrm{X}$ & $\mathrm{X}$ & $\mathrm{X}$ \\
\hline Factitive (F) / Result / Range & $\mathrm{X}$ & $\mathrm{X}$ & $\mathrm{X}$ & - & - & - \\
\hline Locative (L) / Location & $\mathrm{X}$ & $\mathrm{X}$ & - & $\mathrm{X}$ & $\mathrm{X}$ & $\mathrm{X}$ \\
\hline Objective (O) / Object / Patient / Theme & $\mathrm{X}$ & $\mathrm{X}$ & $\mathrm{X}$ & $\mathrm{X}$ & $\mathrm{X}$ & $\mathrm{X}$ \\
\hline Goal $(\mathrm{G})$ & - & $\mathrm{X}$ & $\mathrm{X}$ & - & - & - \\
\hline Measure & - & $\mathrm{X}$ & $\mathrm{X}$ & - & - & - \\
\hline Path & - & $\mathrm{X}$ & - & - & - & - \\
\hline Source & - & $\mathrm{X}$ & - & - & - & - \\
\hline Accompaniment / Comitative & - & - & $\mathrm{X}$ & $\bar{X}$ & - & - \\
\hline Beneficiary / Benefacte & - & - & $\mathrm{X}$ & $\mathrm{X}$ & - & $\mathrm{X}$ \\
\hline Causer / Force & - & - & $\mathrm{X}$ & - & - & $\mathrm{X}$ \\
\hline Manner & - & - & $\mathrm{X}$ & - & - & - \\
\hline Time & - & - & $\mathrm{X}$ & $\mathrm{X}$ & - & - \\
\hline Recipient & - & - & - & - & $\mathrm{X}$ & $\bar{X}$ \\
\hline Possessor & - & - & - & - & $\mathrm{X}$ & $\mathrm{X}$ \\
\hline Content & - & - & - & - & - & $\mathrm{X}$ \\
\hline
\end{tabular}

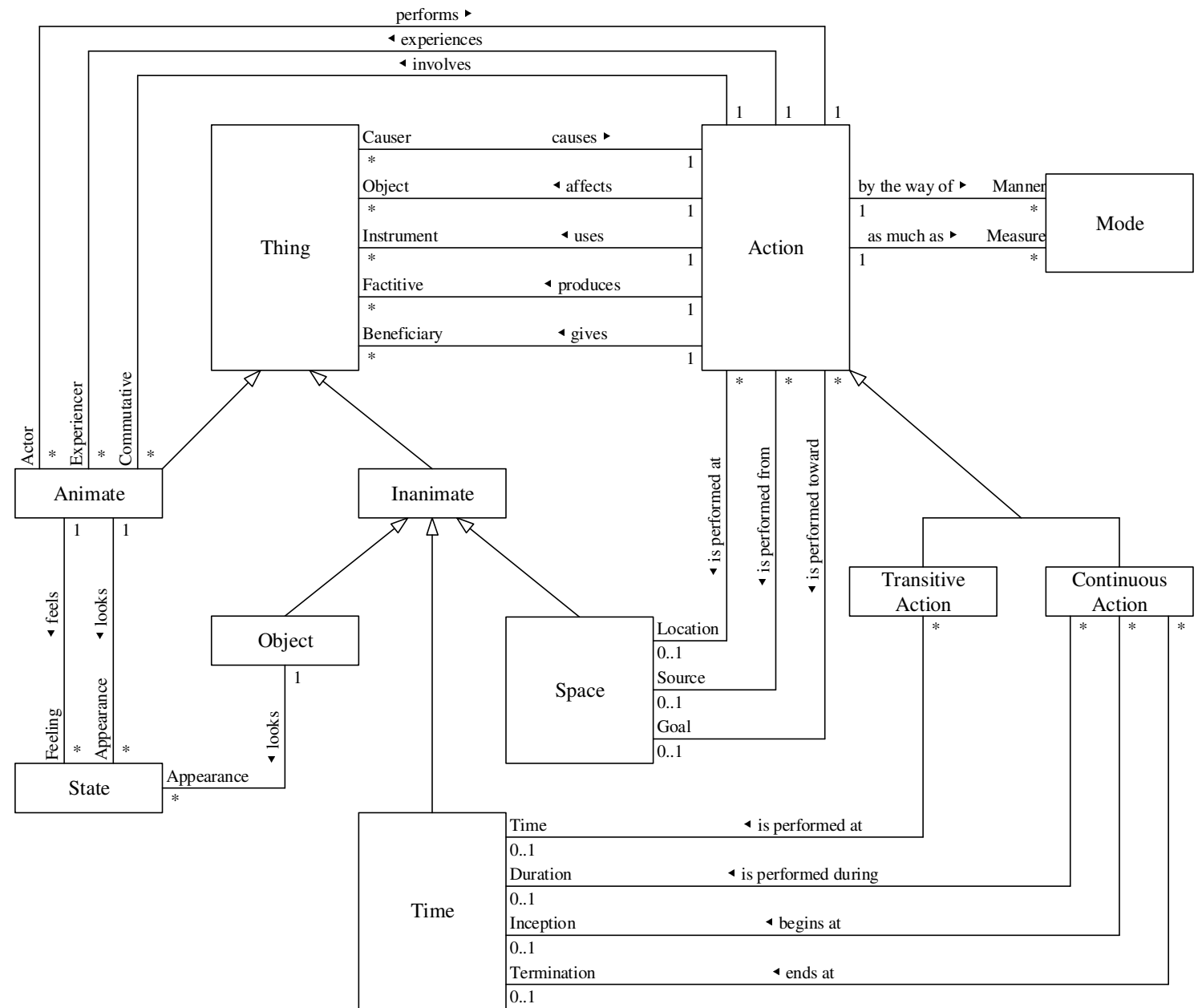

Fig. 1. Object oriented context model. 


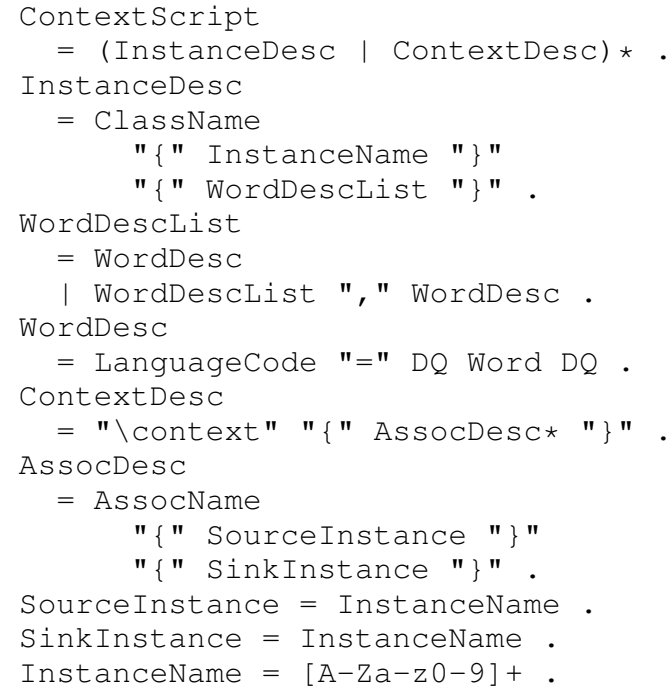

Fig. 2. Syntax of the context description language.

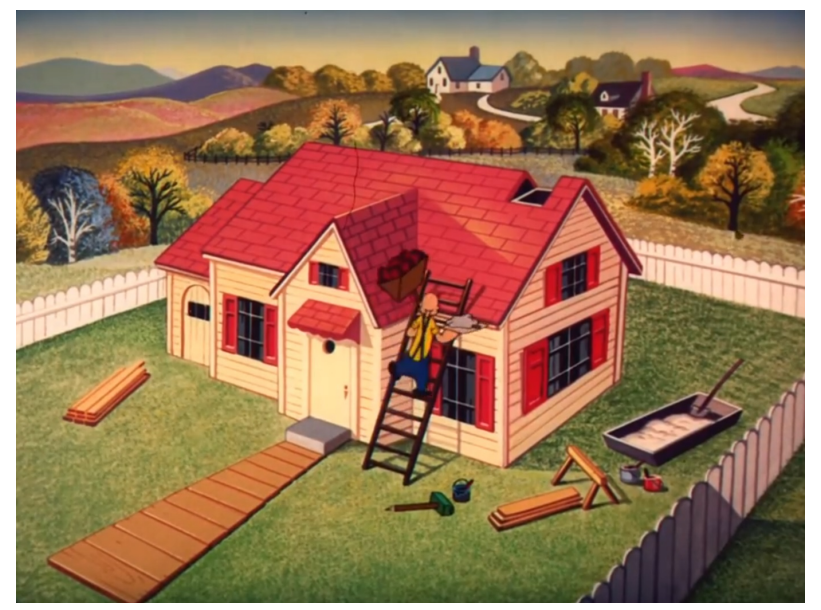

Fig. 3. An example movie scene.

scene by the subjects with ignoring trivial difference of words. Rather, the authors focused on difference of meanings.

In this evaluation, the authors collected forty-two (42) equivalent sentences from different subjects. Eighty-five (85) OOCM associations were identified from these sentences. The sentences and associations are listed in the appendix. The authors checked if these OOCM associations appear in each subject's description one by one. Table III shows the results.

The subjects could identify more associations of the OOCM describing the movie scenes with referencing OOCM than without referencing the OOCM. That means the OOCM can guide the composer to enrich information included in the movie context; therefore, we can generate more types of quizzes based on the movie context.

TABLE III. COMPARISON RESUlTS

\begin{tabular}{|c|r|r|r|}
\hline \multirow{2}{*}{ Approaches } & \multicolumn{3}{|c|}{ Subjects } \\
\cline { 2 - 4 } & $\# 1$ & $\# 2$ & $\# 3$ \\
\hline Without Referencing OOCM & 46 & 47 & 18 \\
\hline With Referencing OOCM & 63 & 55 & 53 \\
\hline
\end{tabular}

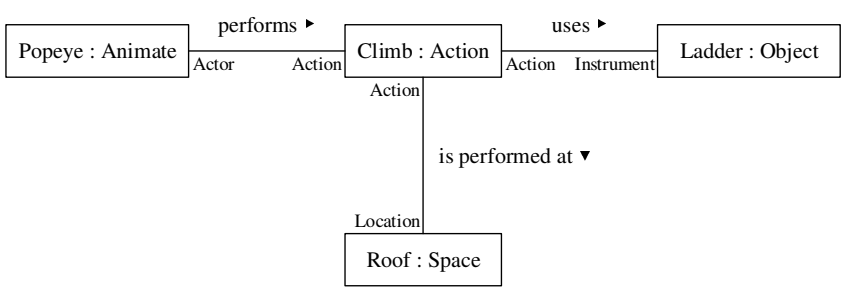

Fig. 4. An example OOCM.

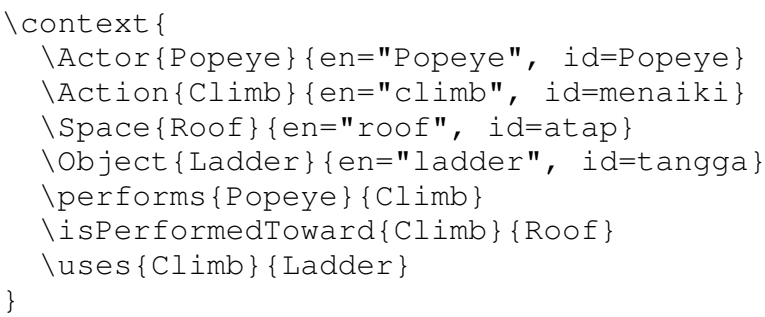

Fig. 5. An example CDL.

\section{CONCLUSION}

This paper presented the concept of the movie based context-aware learning (MBCAL). The learner learns something through quizzes generated depending on the movie context with replaying the movie. In contrast to context-aware ubiquitous learning, the MBCAL system does not require to develop learning applications interacting with physical sensors or smartphones as well as to operate physical systems. Language learning is a promising application of MBCAL.

MBCAL requires less effort for its development and operation than context-aware ubiquitous learning. On the other hand, it requires effort to describe the movie context by human work, since state-of-the-art image and phonetic recognition and understanding technologies can recognize a limited class of the movie context. The authors presented the object-oriented context model (OOCM) which was constructed based on the case grammar concept of natural language processing. The OOCM can guide us to enrich description of the movie context. In the evaluation conducted in this paper, with referencing the OOCM, the subjects can identify and describe more OOCM associations describing the contexts that occur in the movie. Moreover, the authors defined a textual context description language $(\mathrm{CDL})$ that can describe an instance of the OOCM. We can describe movie contexts instantly by using the textual CDL.

\section{ACKNOWLEDGMENT}

This work is partially supported by Directorate of Higher Education (DGHE) of Indonesian Government.

\section{REFERENCES}

[1] Hazriani, T. Nakanishi, K. Hisazumi, and A. Fukuda, A, "A Movie Based Context-Aware Learning System: Its Concept and System," Proc. IEEE 6th Int. Conf. on Technology for Education (T4E), pp. 164-167, December 2014.

[2] Hazriani, T. Nakanishi, and A. Fukuda, "Architecture, Textual Context Description, and Quiz Generation Scheme for the Movie Based Context-Aware Learning System," Proc. 2016 IEEE Region 10 Int. Conf. (TENCON), pp.2412-2415, November 2016. 
[3] H. Ogata and N. Uosaki, "A New Trend of Mobile and Ubiquitous Learning Research: Toward Enhancing Ubiquitous Learning Experiences," Int. J. Mobile Learning and Organisation (IJMLO), Vol. 6, No. 1 pp. 64-78, March 2012.

[4] A. Molnar, "Computers in Education: A Brief History," Int. J. Transforming Education through Technology, Vol. 24, No. 11, pp. 63-68, June 1997.

[5] C. H. S. Kerber, D. Clemens, and W. Medina, "Seeing is Believing: Learning about Mental Illness as Potrayed in Movie Clips," J. of Nursing Education (JNE), Vol. 43, No. 10, p. 479, October 2004.

[6] N. Lumlertgul, N. Kijpaisalratana, N. Pityaratstian, and D. Wangsaturaka, "Cinemeducation: A Pilot Student Project Using Movies to Help Stident Learn Medical Professionalism, Medical Teacher," Informa Healtcare LTd. Vol. 31, pp. e327-e332, August 2009.

[7] W. Jungraithmayr and W. Weder, "The Technique of Orthotopic Mouse Lung Transplantation as a MovieImproved Learning by Visualisation," American J. of Transplantation, Vol. 12, No. 6 pp. 1624-1626, March 2012.

[8] D. Chan and C. Herrero, Using Film to Teach Languages, Cornerhouse, 2010.

[9] M. Ismaili, "The Effectiveness of Using Movies in the EFL Classroom: A study Conducted at South East European University," Academic Journal of Interdisciplinary Studies, Vol. 2, No. 4 pp. 121-132, May 2013.

[10] P. S. Chiu, Y. H. Kuo, Y. M. Huang, and T. S. Chen, "The Ubiquitous Learning Evaluation Method Based on Meaningful Learning," Proc. 3rd Int. Conf. on Computer Education (ICCSE), pp.257-264, July 2008.

[11] G. J. Hwang, C. C. Tsai, and S. J. H. Yang, "Criteria, Strategies and Research Issues of Context-Aware Ubiquitous Learning," J. of Education Technology \& Society (ET \& S), Vol. 11, No. 2 pp.81-91, April 2008.

[12] H. Ogata, R. Akamatsu, and Y. Yano, "Computer Supported Ubiquitous Learning Environment for Vocabulary Learning Using RFID Tags," Proc. IFIP TC3 Technology Enhanced Learning Workshop (TeL04), pp. 121-130, August 2004

[13] S. Yahya, E. A. Ahmad, and K. A. Jalil, "The Definition and Characteristics of Ubiquitous Learning: A Discussion," International Journal of Education and Development Using ICT (IJEDICT) Vol. 6, No. 1 pp. 117-127, January 2010.

[14] Hazriani, T. Nakanishi, and A. Fukuda, "Introducing the Case Grammar Concept to Object Oriented Movie Description," Proc. 2016 IEEE Int. Conf. on Teaching, Assesment, and Learning for Engineering (TALE), pp. 261-265, December 2016.

[15] J. Fillmore, The Case for Case, Proc. of Texas Syposium on Language Universals April 1967

[16] D. Jurafsky and J. H. Martin, "Speech and Language Processing: Semantic Role Labeling," 3rd Edition draft, 2017, pp. 377-395.

[17] V. Parunak, "Case Grammar: A Linguistic Tool for Engineering AgentBased System," Journal or Conference, Doi: 10.1.1.58.7325, 1995.

[18] SIL International, "Semantic Role," https://glossary.sil.org/term/ semantic-role/, Last Accessed on April 1st, 2018.

[19] ISO 639-1:2002, Codes for the Representation of Names of Languages / Part 1: Alpha-2 Code, 2002.

[20] ISO 639-3:2007, Codes for the Representation of Names of Languages / Part 3: Alpha-3 Code for Comprehensive Coverage of Languages, 2007

[21] D. Tendlar (direction), M. Reden, T. Moore (animation), I. Klein (story), A. Loeb (scenics), and W. Sharples (music), Insect to Injury, Popeye the Sailor Series, 1956.

\section{APPENDIX}

In the evaluation conducted in Section $\mathrm{V}$, the authors collected fourty-two (42) equivalent sentences from three subjects. Each item in the enumeration below shows an equivalent sentences in the first line and the OOCM associations derived from the sentence in the following line(s). The fourty-two equivalent sentences derives eighty-five (85) OOCM associations.

1) The surroundings of the house looks shady and cool. Object(the surroundings of the house) looks Appearance(shady) Object(the surroundings of the house) looks Appearance(cool)
2) Popeye climbs to the roof by a ladder. Actor(Popeye) performs Action(climb) Action (climb) isPerformedToward Goal(the roof)

Action $($ climb $)$ uses Instrument $(a$ ladder $)$

3) Popeye lays bricks very quickly.

Actor(Popeye) performs Action(lay)

Action(lay) affects Object(bricks)

Action(lay) byTheWayOf Manner(quickly)

4) Popeye feels satisfied. Animate(Popeye) feels Feeling(satisfied)

5) Popeye slides down the stair.

Actor(Popeye) performs Action(slide down)

Action(slide down) isPerformedAt Location(the stair)

6) Popeye puts in the mailbox in front of the fence.

Actor(Popeye) performs Action(put in)

Action(put in) affects Object(the mailbox)

Action(put in) isPerformedAt Location(in front of the fence)

7) Popeye wears a yellow T-Shirt.

Actor(Popeye) performs Action(wear)

Action(wear) affects Object(a yellow T-Shirt)

8) Popeye writes his name on the mailbox.

Actor(Popeye) performs Action(write)

Action(write) affects Object(his name)

Action(write) isPerformedAt Location(on the mailbox)

9) The insects eat up the mailbox.

Actor(the insects) performs Action(eat up)

Action(eat up) affects Object(the mailbox)

10) Popeye closes the gate.

Actor(Popeye) performs Action(close)

Action(close) affects Object(the gate)

11) Popeye is in a panic.

Animate(Popeye) looks Appearance(in a panic)

12) Popeye blocks the insects.

Actor(Popeye) performs Action(block)

Action(block) affects Object $($ the insects)

13) Popeye catches the insects into the trash can.

Actor(Popeye) performs Action(catch)

Action(catch) affects Object $($ the insects)

Action $($ catch) isPerformedToward Goal(the trash can)

14) The insects escape from the trash can.

Actor(the insects) performs Action(escape)

Action(escape) isPerformedFrom Source(the trash can)

15) Popeye repairs the fence by the hammer.

Actor(Popeye) performs Action(repair)

Action(repair) affects Object(the fence)

Action(repair) uses Instrument(the hammer)

16) Popeye looks stressful.

Animate(Popeye) looks Appearance(stressful)

17) Popeye casts out the insects with wheels.

Actor(Popeye) performs Action(cast out)

Action(cast out) affects Object(the insects)

Action(cast out) uses Instrument(wheels)

18) The insects run towards the river.

Actor(the insects) performs Action(run)

Action(run) isPerformedToward Goal(the river)

19) The insects ruin the bridge.

Causer(the insects) causes Action(ruin)

Action(Action) affects Object(the bridge)

20) Popeye falls into the river.

Experiencer(Popeye) experiences Action(fall)

Action(fall) isPerformedToward Goal(the river)

21) The insects rush for the house.

Actor(the insects) performs Action(rush)

Action(rush) isPerformedToward Goal(the house)

22) Popeye digs a trench by the shovel.

Actor(Popeye) performs Action(dig)

$\operatorname{Action}(\mathrm{dig})$ affects $\mathrm{Object}($ a trench)

Action(dig) uses Instrument(the shovel)

23) Popeye fills the trench with water.

Actor(Popeye) performs Action(fill)

Action(fill) affects Object(the trench)

Action(fill) uses Instrument(the water)

24) The insects look angry.

Animate(the insects) looks Appearance(angry)

25) Popeye feels secure.

Animate(Popeye) feels Feeling(secure) 
26) Popeye enters to the house.

Actor(Popeye) performs Action(enter)

Action(enter) isPerformedToward Goal(the house)

27) Popeye locks the door.

Actor(Popeye) performs Action(lock)

Action (lock) affects Object (the door)

28) Popeye reads a book.

Actor(Popeye) performs Action(read)

Action(read) affects Object (a book)

29) The insects cross the trench with a can.

Actor(the insects) performs Action(cross)

Action(cross) isPerformedAt Location(the trench)

Action(cross) uses Instrument $(a$ can $)$

30) The insects enter to popeye's house.

Actor(the insects) performs Action(enter)

Action(enter) isPerformedToward Goal(Popeye's house)

31) Popeye looks shocked.

Animate(Popeye) looks Appearance(shocked)

32) The insects destroy the house.

Causer(the insects) causes Action(destroy)

Action(destroy) affects Object(the house)

33) Popeye falls into the bathtub.

Actor(Popeye) performs Action(fall)

Action(fall) isPerformedToward Goal(the bathtub)

34) The insects look satiate.
Animate(the insects) looks Appearance(satiate)

35) Popeye eats spinach.

Actor(Popeye) performs Action(eat)

Action(eat) affects Object(spinach)

36) Popeye looks strong.

Animate(Popeye) looks Appearance(strong)

37) Popeye rebuilds his house with the metal.

Actor(Popeye) performs Action(rebuild)

Action(rebuild) affects Object(his house)

Action(rebuild) uses Instrument (the metal)

38) Popeye rebuilds the house in a moment.

Actor(Popeye) performs Action(rebuild)

Action(rebuild) affects Object(his house)

Action(rebuild) byTheWayOf Manner(in a moment)

39) The insects look tired.

Animate(the insects) looks Appearance(tired)

40) Popeye triumphs over the insects.

Actor(Popeye) performs Action(triumph over)

Action(triumph over) affects Object(the insects)

41) The insects eat a cigar.

Actor(the insects) performs Action(Action)

Action(eat) affects Object(a cigar)

42) Popeye feels relieved.

Animate(insects) feels Feeling(relieved) 